\title{
The Analysis of Reverse Logistics Model in the E-commerce Models
}

\author{
Lingling-Chen ${ }^{1,2}$, Wei- $\mathrm{Li}^{2}$ and Huiying-Zhai ${ }^{2}$ \\ ${ }^{1}$ Wuhan university of technology, Wu han, China, 430000 \\ ${ }^{2}$ Yanching Institute of Technology,Langfang, China, 063000 \\ (Corresponding author: Wei-Li,1350414148@qq.com)
}

\begin{abstract}
The computer networks have rapidly developed, and its field of application is also vigorously rising for the past many years, especially electronic commerce. However, due to each link of the supply chain will return a large number of products, so e-commerce model in reverse logistics becomes the first difficult problem. In order to solve the problem of the return of enterprise products, we apply the principles of efficiency savings, and allow more businesses to benefit. Meanwhile Reverse Logistics Model concept came into being. This paper focuses on the background of reverse logistics and the current problems, in the same time, conduct a detailed analysis of reverse logistics model. We adopt QS_R strategies to improve and provide case which let people understand easily. Through this research we hope that government agencies and businesses can make more highly valued the importance of reverse logistics, and have a preliminary understanding reverse logistics models. Our aim is to better make outstanding contributions to our social-economic.
\end{abstract}

Keywords: $\quad$ E-commerce, mode, Reverse Logistics, Model Analysis

\section{Introduction}

The rapid development of computer network ushered in today's information age, and the e-commerce also rapidly develop. It not only plays a impact role of the corporate planning, production, organization, and product flows aspects, but also can greatly simplify the business transaction process, reducing costs, and promote global economic development. It will be the development trend of the information age business activities. Business transactions is very convenient and efficient, however, the existing problems can not be ignored. Because the procurement of goods return rate which use the e-commerce means is much higher than procurement of goods return rate which use the traditional business model. It is necessary to study and solve the basic problem of reverse logistics delay. This paper aims to analyzes the reverse logistics through e-commerce model, and combine the e-commerce with the reverse logistics. At the same time, it does not circumvent the current deficiencies. We make recommendations to help the domestic and foreign enterprises improve degree of attention to reverse logistics. Thereby we can save costs, and operate effectively.

\section{Basic Theory}

\subsection{Basic Theory of Reverse Logistics}

\subsubsection{Definition of Reverse Logistics}

With the development of science and technology, now, the industry generally accepted definition of reverse logistics: for forward logistics, it is opposite on the running link. It 
includes raw materials, intermediate products, end products which are returned from the manufacturer to the consumer or the process of rational treatment of the initial part of the supply chain.

\subsubsection{Reverse Logistics Classification}

Reverse Logistics based on causes, paths, different treatment methods and its industrial patterns to classify in the following table.

Table 1. Reverse Logistics Classification

\begin{tabular}{|c|c|c|c|c|}
\hline Classification & Time & Factors & $\begin{array}{l}\text { Processing } \\
\text { Methods }\end{array}$ & Examples \\
\hline $\begin{array}{l}\text { Complaints Return } \\
\text { The quality of the product }\end{array}$ & short term & $\begin{array}{l}\text { Marketing } \\
\text { customer } \\
\text { satisfaction } \\
\text { service }\end{array}$ & $\begin{array}{c}\text { Validation } \\
\text { checks, Shipping } \\
\text { and Returns } \\
\text { Replenishment }\end{array}$ & $\begin{array}{l}\text { Electronic } \\
\text { products such as } \\
\text { mobile phones, } \\
\text { computers, etc. }\end{array}$ \\
\hline $\begin{array}{c}\text { Terminal Return } \\
\text { After using completely } \\
\text { product which need be } \\
\text { treated }\end{array}$ & long term & $\begin{array}{l}\text { Laws and } \\
\text { regulations }\end{array}$ & $\begin{array}{l}\text { Reproduction, } \\
\text { recycling }\end{array}$ & $\begin{array}{l}\text { Reproduction of } \\
\text { electronic } \\
\text { products, carpet } \\
\text { circulation, tire } \\
\quad \text { repair } \\
\text { Household } \\
\text { appliances }\end{array}$ \\
\hline $\begin{array}{c}\text { Business return } \\
\text { Refund payment of unused } \\
\text { items }\end{array}$ & $\begin{array}{l}\text { short to } \\
\text { medium } \\
\text { term }\end{array}$ & Asset Recovery & $\begin{array}{l}\text { reuse, } \\
\text { reproduction, } \\
\text { recycling, } \\
\text { handling }\end{array}$ & $\begin{array}{c}\text { Computer } \\
\text { components and } \\
\text { print cartridge } \\
\text { Retail } \\
\text { manufacturers } \\
\text { backlog of } \\
\text { inventory, } \\
\text { clothing, daily } \\
\text { chemical } \\
\text { products }\end{array}$ \\
\hline $\begin{array}{c}\text { Repair Return } \\
\text { Defective or damaged } \\
\text { products }\end{array}$ & $\begin{array}{l}\text { medium } \\
\text { term }\end{array}$ & $\begin{array}{l}\text { Marketing } \\
\text { Laws and } \\
\text { regulations }\end{array}$ & $\begin{array}{l}\text { Maintenance } \\
\text { Handling }\end{array}$ & $\begin{array}{l}\text { Defective } \\
\text { household } \\
\text { appliances, spare } \\
\text { parts, mobile } \\
\text { phones }\end{array}$ \\
\hline $\begin{array}{l}\text { Production scrap and } \\
\text { substandard goods } \\
\text { Scrap and substandard } \\
\text { goods in production } \\
\text { process }\end{array}$ & $\begin{array}{l}\text { shorter } \\
\text { term }\end{array}$ & $\begin{array}{l}\text { Economic laws } \\
\text { and regulations }\end{array}$ & $\begin{array}{l}\text { Recycling, } \\
\text { reproduction }\end{array}$ & $\begin{array}{l}\text { pharmaceutical } \\
\text { industry, steel } \\
\text { industry }\end{array}$ \\
\hline \multirow{2}{*}{$\begin{array}{l}\text { Package } \\
\text { Packaging materials and } \\
\text { products carrier }\end{array}$} & \multirow{2}{*}{ short term } & economic & reuse & $\begin{array}{l}\text { Pallets, crates, } \\
\text { containers }\end{array}$ \\
\hline & & $\begin{array}{l}\text { Laws and } \\
\text { regulations }\end{array}$ & Recycling & Packing bags \\
\hline
\end{tabular}




\section{The Reason for the Rapid Development of E-commerce Mode of Reverse Logistics and Problems}

\subsection{Cause of E-commerce Activities in Reverse Logistics}

This paper only refers to return, replacement reverse logistics. The main reasons of reverse logistics in e-commerce activities in the following:

(1) Inconsistent information

Such as making online shopping, consumers received the information which is product images that specially treated or some descriptive texts. The consumer can not have a comprehensive and objective understanding about goods with such information. So in this case, the consumer will inevitably lead to the return situation which is understandable.

(2) Increasing competitive advantage

Due to the current market economy, there are some competition between the same industry and different industries businesses. Businesses have numerous marketing tools, for example, they set up shipping return policy to attract the attention of consumers. However, we still can not avoid the phenomenon of return because of the gap between virtual and reality. And the return data is still on the rise.

\subsubsection{Reverse Logistics Management in the E-commerce}

To cope with these problems, we can consider the solutions from the point of view in the following:

(1) Prevention of reverse logistics

When the manufacturer or other operating manufacturers in considering how to solve this difficult problem, we suggest that they can fully take into account their own manufacturers selling to merchandise return issue on the market in the beginning of e-commerce website design. They should particularly pay attention to the following several aspects:

1) We recommend businesses when they design their own website to provide useful commodity information as much as possible. It not only helps consumers make the right judgments, but also can reduce the returns.

2) We recommend that businesses have to improve the system, for example, they have a relatively complete system of control orders. Consumers can have time to verify whether they really need the goods in a period of time after the order in this system. It is convenient and save trouble. It also avoids occurring the phenomenon that consumers return again after receipt goods.

(2) Treatment of existing reverse logistics

We found that the phenomenon of reverse logistics can not be avoided by analyzing the content of the above. But we can pay attention to handling existing reverse logistics phenomenon, and guarantee efficient about sales service. On the one hand we can actively develop our return policy, on the other hand we can establish a reasonable product recovery system. They should pay attention to the following points:

1) When businesses website design, they should set the position which includes how to return and return conditions that consumers can find easily. It is more user-friendly and easy-oriented.

2) When businesses design packaging, they can indicate the way and policies of return in detail. In the same time, recommend that consumers do not throw away the packaging 
of goods in a short time, to prevent the method nowhere to be found when they want to return. Therefore, reverse logistics is very important. Businesses need the high degree attention to it.

\section{Analysis of Reverse Logistics Model in the E-commerce Model}

\subsection{Model Establishment}

We can assume that there is a e-commerce companies purchasing a product from a supplier. Then first the supplier of the product through its own logistics agency or he may take a third-party logistics company to transport. Our assumptions are based a medium-sized city as a region in the actual operation. The detailed design of the system operation method shown in Figure 4-1. If consumers feel dissatisfied with goods that delivery by some distribution centers and distribution and they are going to take return. Firstly, they must contact the third-party testing point in their area for products testing.

An assumption of the model includes the following four points:

First, we assume that demand and return amount of online sales of products follows Poisson distribution in $\mathrm{j}$ transportation hub area

(1) First, we assume that demand and return amount of online sales of products follows Poisson distribution in $\mathrm{j}$ transportation hub area(hereinafter referred to as $D C_{j}$ $\mathrm{j}=1, \cdots \cdots, \mathrm{n})$ ). We assume that the demand is $\lambda_{j}$, return amount is $\gamma_{j}$; Generally speaking $\gamma_{j}\left\langle\lambda_{j} \quad(\mathrm{j}=1, . . \cdots \mathrm{n})\right.$. Products demand (return amount) sold on online is determined by the different transport hub. Because the transport hub is different, and regional services are also different. We found that the total amount of product demand and returns in $\mathrm{B} 2 \mathrm{C}$ e-commerce businesses also obey Poisson distribution. We can use letters $\lambda^{0}$ and $\gamma^{0}$ to represent. And there are

$$
\begin{aligned}
& \lambda_{0}=\sum_{j=1}^{n} \lambda_{j} \\
& \gamma^{0}=\sum_{j=1}^{n} \gamma_{j}
\end{aligned}
$$

here: $\gamma^{0}$ is less than $\lambda^{0}$, So they should always orders to manufacturers.

(2) We assume that the number of radiated regional of third-party testing point and the specific locations in each distribution center are determined well in advance. And this is not going to change.

(3) Theoretically speaking, only e-commerce companies apply placing orders to supplier, and then the supplier will ship required goods to distribution centers. When consumers submit their orders online, products will be immediately transported from the distribution center where consumers within the corresponding region to the consumer. But in the actual running operation, e-commerce Company receives orders which are submitted by consumer, and its interval time is usually within 24 hours. The time that suppliers delivery goods to distribution centers is often more than 24 hours.

(4) Ordering cost which is constant factor will take effect in each order. 


\subsection{Model Analysis}

The ultimate goal of B2C e-commerce businesses is to seek maximum benefits. However, if we establish more third-party testing point in the same area, and consumer's satisfaction will be higher. Therefore, incurred costs will also increase. The purpose of our established model is to balance an imbalance which is mentioned above. So those make companies get the most benefit. We already have preliminary ideas from the previous analysis. Therefore, we based on both foregoing points and we will express B2C companies' the largest expected profit with bi-level programming model.

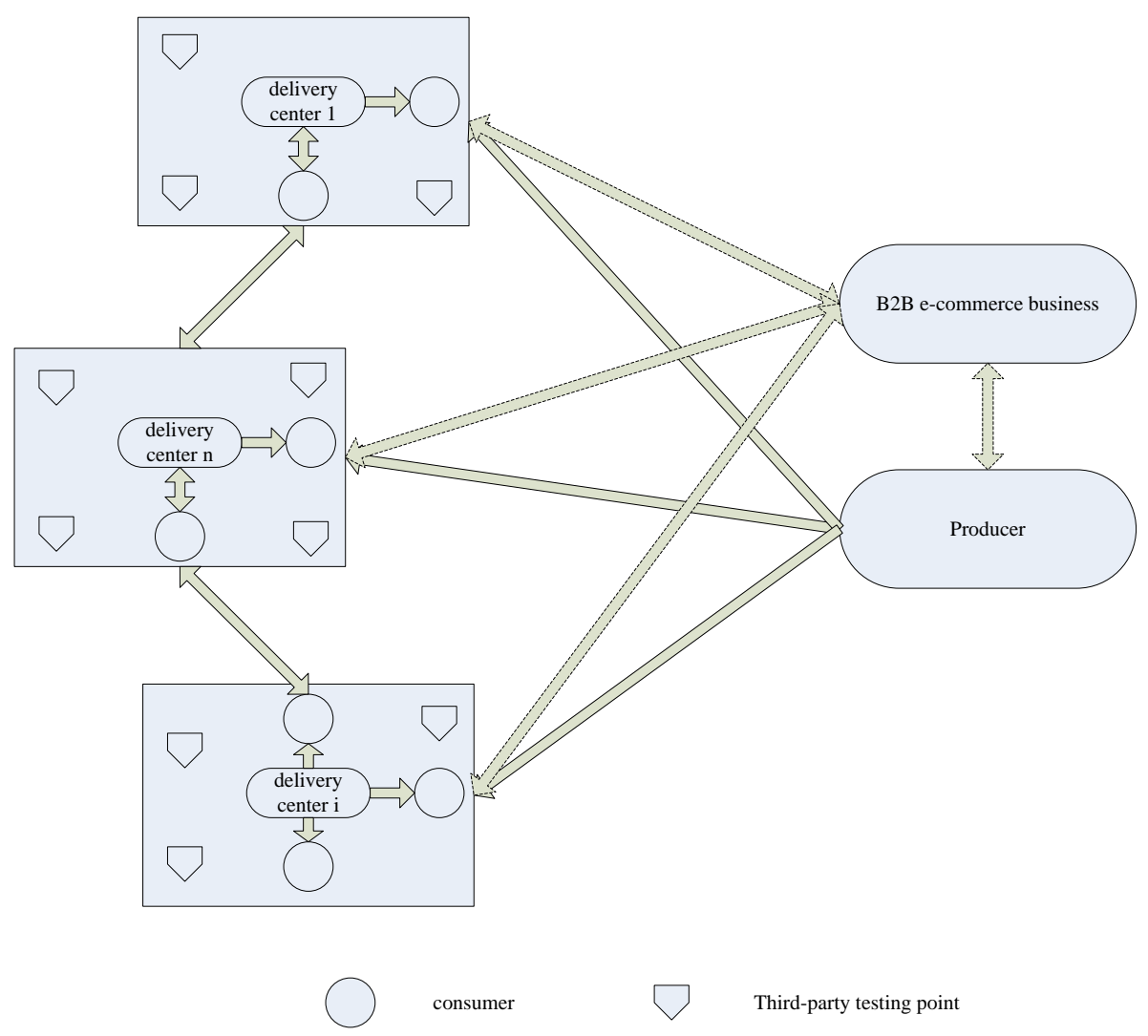

Figure 1. Operating System

First step, through research we can know that companies develop return policy sooner, and it will attract the more number of consumers. So convenient return policy has influence on demand. We represent ease of return by the number and location of third-party monitoring points in this paper. Through the above figure, we use i represents the entire covered area of transportation hub. We use $A_{i}$ represents the number $\mathrm{m}$ third-party testing agency radiation area in the $D C_{i}$ area. But if it is more than one third-party testing agency of the total radiation area, we should how to calculate it? We illustrate it with $A_{i 1}$ and $A_{i 2}$, which is that $A_{i 1} \cup A_{i 2}$ equals $A_{i 1} A_{i 2}-A_{i 1} \cap A_{i 2}$. In order to calculate, we assume that the third-party testing point radiation region for the center of the circle, and the radius is $\rho$. We assume that the distribution area is a circular in the model. The distribution center is center of the circle, and the radius is ${ }_{i}$. And outside of the circle is suburban area. 


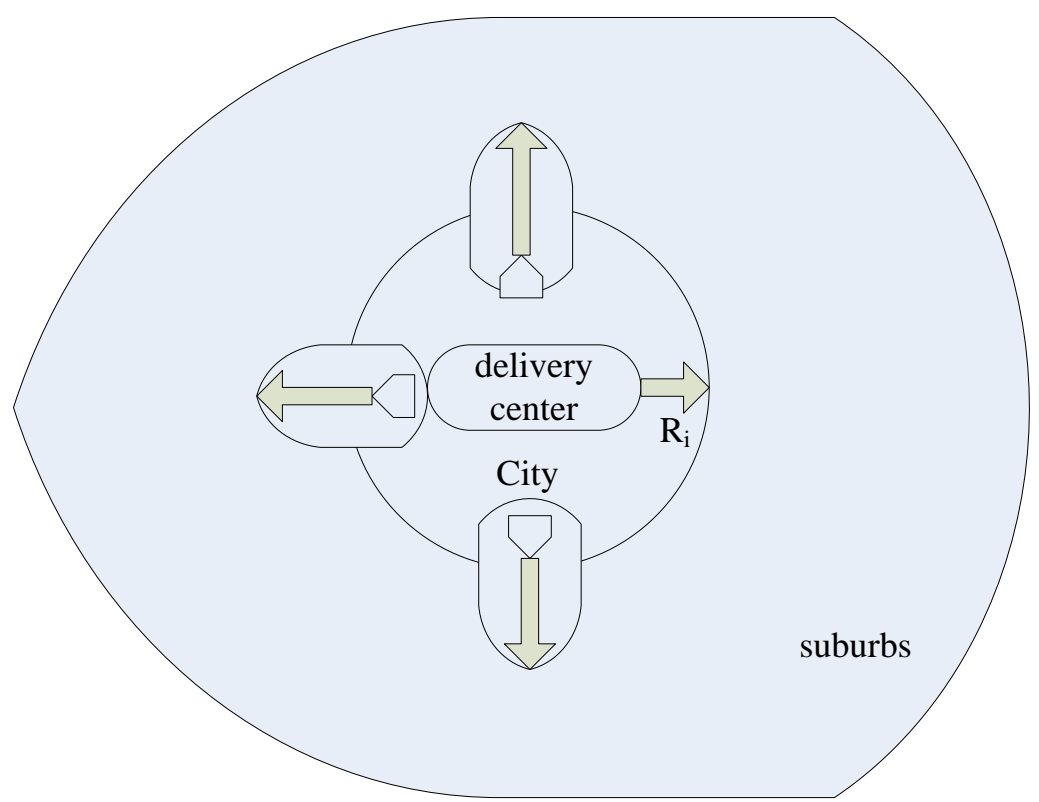

Figure 2. The Illustrated Map of Region i

The expected final demand is as follows:

$$
D D_{i}=\left\{\begin{array}{l}
\text { 1suburbs }(\text { Outsidethearea of thecenter circle }) \\
2 \text { city }(\text { Regionalcenters within the circle })
\end{array}\right.
$$

$\varepsilon_{i}>1$ and we can expect ${ }^{\varepsilon_{i}}$ by population reporting and comprehensive purchasing power region $i$.

We assume that $\mathrm{Ai}(\mathrm{s})(\mathrm{Ai}(\mathrm{d}))$ are not (in) inside all regions of the center circle in region i. Therefore, the number $\mathrm{m}$ 3CS radiation area Aim represents the demand of the region:

$$
A_{\text {im }}=A_{i m}(S){ }_{+} \varepsilon_{i} A_{i m}(d)
$$

In the same, $A_{j}$ represents the demand of the region $\mathrm{j}$ :

$$
A_{i=} A_{i}(S)_{+} \varepsilon_{i} A_{i}(d)
$$

Whether choose decision of 3CS, we can be expressed as the following formula:

$$
\gamma_{i m}= \begin{cases}1 & \text { Select in theregion provided the } \mathrm{K} \text { m of } 3 \mathrm{C} \\ 0 & \text { Not in theregion }\end{cases}
$$

$\mathrm{I}_{\mathrm{j}}$ is the total number of possible establishment monitoring points within the region In summary, the ease of return can be expressed as following:

$$
\phi_{i}=\frac{U_{m} A_{i m} r_{i m}}{A_{i}} \xi(0<\xi \leq 1)
$$

The relationship between the demand and $3 \mathrm{CS}$ is:

$$
\lambda_{i}=\left(1+\phi_{i}\right) \lambda_{i}^{\prime}
$$


$\lambda_{i}^{\prime}$ is demand where have no $3 \mathrm{CS}$ (it do not produce reverse logistics) in the region $\mathrm{i}$.

There exists certain correlation between the amount of the demand rate and returns amount in practice. We can simply express as flowing:

$$
\gamma_{i}=n \% \lambda_{i}
$$

$\mathrm{n} \%$ is 0.1 in this paper, specific things due to different circumstances. We will discuss how to choose the methods of $3 \mathrm{CS}$ within each region, for example region $\mathrm{i}$ :

$$
A_{i 1} \geq A_{i 2} \geq A_{i m} \geq \ldots \ldots A_{i I_{i}} \quad \mathrm{~m} \in I_{i},
$$

$I_{i}$ is equal to the total number of potential 3CS in i region. For example, if $I_{i}=3$, there are $33 \mathrm{CS}$ in the region $\mathrm{i}$.

Suppose MA (1) represents the largest radiation area in one 3CS within region i:

$$
\operatorname{MA}(1)=A_{i 1}
$$

So MA (2), MA (3)... MA $\left({ }^{I_{i}}\right)$ represents any $23 \mathrm{CS}, 33 \mathrm{CS}$, or ${ }^{I_{i}}$ 3CS.

It can radiate total maximum area which we express by the formula:

\section{MAX}

$$
\mathrm{m}, \mathrm{s} \in I_{i}
$$

\section{$M A X$}

$$
\operatorname{MA}(3)=A_{i m} \cup A_{i s} \cup A_{i g}
$$

$\mathrm{m}, \mathrm{s}, \mathrm{g} \in I_{i}$

$$
\left(\mathrm{P}^{I_{i}}\right)
$$

$$
\mathrm{MA}(2)=A_{m k} \cup A_{m s}
$$

All the $\mathrm{k} \in I_{i}$

After our decision, we assume that the number of $3 \mathrm{CS}$ is ${ }^{r_{i}}$, in the same time, we assume ${ }^{r_{i}}>0$. So 3CS' optimal location problem can be expressed as (Pri) in the region $\mathrm{j}$. We see that the maximum total radiation area is MA $\left({ }^{r_{i}}\right)$. Correspondingly, the most convenient degree of return expressed as $\phi_{i}=\left[M A\left(r_{i}\right) / A i\right] . \zeta$, when $r_{i}$ becomes larger, $\phi_{i}$ also becomes larger. Therefore, remand $\lambda_{i}$ will larger. However, $\mathrm{r}_{\mathrm{i}}$ is more larger, the cost of 3CS is more higher. Therefore, we need to consider the number 3CS has influence on B2C e-commerce businesses' profit contribution. 
Second step, establish the relational model of sitting and inventory systems.

Since transportation costs can not be eliminated in the course of transportation. The average distance from distribution center to the consumer is ${ }{ }_{i}$. So the average costs of the total transport in unit time are:

$$
C_{i}=\sum_{i=1}^{n} \delta_{i}^{t} M_{i}\left(\lambda_{i}+\gamma_{i}\right)
$$

Combined with the previously mentioned content, in pursuit of the maximize benefits as the goal, we can use a bi-level programming model to express:

$$
\begin{gathered}
\underset{Q, S_{1} \ldots S_{n} ; r_{i} \ldots r_{n}}{\operatorname{Max}} \\
\prod\left(Q, S_{1} \ldots S_{n} ; r_{i} \ldots r_{n}\right)=p\left(\lambda^{0}-\gamma^{0}\right)-\left\{c\left(\lambda^{0}-\gamma^{0}\right)+C_{Q S_{-} R}+\sum_{i=1}^{n} \delta_{i}^{t} r_{i}+\sum_{i=1}^{n} \delta_{i}^{t} M_{i}\left(\lambda_{i}+\gamma_{i}\right)\right\} \\
0 \leq r_{i} \leq I_{i}, \quad \mathrm{i}=1,2, \ldots, \mathrm{n} \quad r_{i} \text { is the integer, } \mathrm{i}=1,2, \ldots, \mathrm{n} \\
C_{Q S_{-} R}=K\left(\frac{\lambda^{0}-\gamma^{0}}{Q}\right)+\sum_{i=1}^{n} \delta_{i}^{m} Q_{i}\left(Q S_{-} R\right)+\sum_{i=1}^{n} \delta_{i}^{a} B_{i}\left(Q S_{-} R\right)+\delta_{f}\left(\sum_{i=1}^{n} \sum_{x=-\infty}^{-1}(-x) u_{i}(x)\right)
\end{gathered}
$$

\footnotetext{
$S_{i}$ is the integer, Q is the integer, $\mathrm{i}=1, \ldots \mathrm{n}$
}

In summary, most of the domestic e-commerce enterprises' scale is not great. So we put all the potential combinations of $3 \mathrm{CS}$ methods into the formula to get the minimum cost of inventory. Further, we analyze and come to maximum benefit of e-commerce enterprises.

\subsection{Application of the Model}

We examine the effect of the above established model QS_R strategy after actual

\begin{tabular}{|c|c|c|c|c|c|c|c|c|c|c|c|}
\hline \multirow[b]{2}{*}{$\lambda$} & \multirow[b]{2}{*}{$\gamma$} & \multirow[b]{2}{*}{$\begin{array}{c}\text { delivery } \\
\text { time }\end{array}$} & \multirow[b]{2}{*}{$\mathrm{K}$} & \multicolumn{4}{|c|}{ Independent inventory control } & \multicolumn{4}{|c|}{ QS_R strategy } \\
\hline & & & & $\hat{Q}_{i}^{*}$ & $\hat{S}_{i}^{*}$ & $\begin{array}{c}\text { Cost } \\
\text { i }\end{array}$ & $\begin{array}{l}\text { Total } \\
\text { cost }\end{array}$ & $Q_{i}^{*}$ & $S_{i}^{*}$ & $\begin{array}{l}\text { Total } \\
\text { cost }\end{array}$ & $\begin{array}{c}\text { Saving } \\
\text { costs } \\
*(\%)\end{array}$ \\
\hline & & & & 17 & 36 & 29.4 & & & 31 & & \\
\hline & & & & 16 & 35 & 31.8 & & & 31 & & \\
\hline & & 3 & $\begin{array}{l}2 \\
8\end{array}$ & 18 & 35 & 32.4 & 101.1 & 34 & 28 & 80.5 & 20.69 \\
\hline & & & & 20 & 36 & 33.5 & & & 33 & & \\
\hline & & & & 18 & 38 & 35 & & & 33 & & \\
\hline 4 & 2 & 3 & 2 & 9 & 11 & 16.3 & 79.4 & 25 & 8 & 65.4 & 17.20 \\
\hline
\end{tabular}
application. Table 2 reflects the comparative performance between QS_R strategy and individual inventory control. Its results are very apparent.

Table 2. Comparison Chapter of Independence Inventory and Strategies Control 


\begin{tabular}{|c|c|c|c|c|c|c|c|c|c|c|c|}
\hline & & & 2 & & & & & & & & \\
\hline 7 & 1 & & & 15 & 25 & 26.8 & & & 21 & & \\
\hline \multirow[t]{10}{*}{15} & 3 & & & 20 & 41 & 36.3 & & & 39 & & \\
\hline & & 1 & $\begin{array}{l}3 \\
0\end{array}$ & 10 & 11 & 18.1 & 90.7 & 30 & 9 & 72.5 & 19.80 \\
\hline & & & & 17 & 25 & 30.6 & & & 22 & & \\
\hline & & & & 24 & 48 & 41.9 & & & 41 & & \\
\hline & & 2 & $\begin{array}{l}3 \\
0\end{array}$ & 9 & 14 & 17.8 & 86.5 & 28 & 10 & 72.8 & 15.44 \\
\hline & & & & 16 & 31 & 29.2 & & & 28 & & \\
\hline & & & & 21 & 54 & 39.7 & & & 52 & & \\
\hline & & 3 & $\begin{array}{l}3 \\
1\end{array}$ & 10 & 15 & 17.8 & 95.0 & 32 & 10 & 79.8 & 16.42 \\
\hline & & & & 18 & 34 & 32.8 & & & 29 & & \\
\hline & & & & 24 & 57 & 44.0 & & & 58 & & \\
\hline
\end{tabular}

Compared with the QS_R strategy and the independent inventory control, through the quantity of saving costs, we have made a numerical analysis respectively on demand (return amount) $\mathrm{x}$ with the same system variables in the same distributions and different distribution case in each region. Analysis of the results reveals that QS_R strategy has the more obvious advantages the former two cases. We want to emphasize that fixed ordering cost $\mathrm{K}$ and delivery time $\mathrm{r}$ have a certain effect on saving cost between the QS_R strategy and the independent inventory control. This conclusion can be seen in figure 2 and figure 3.

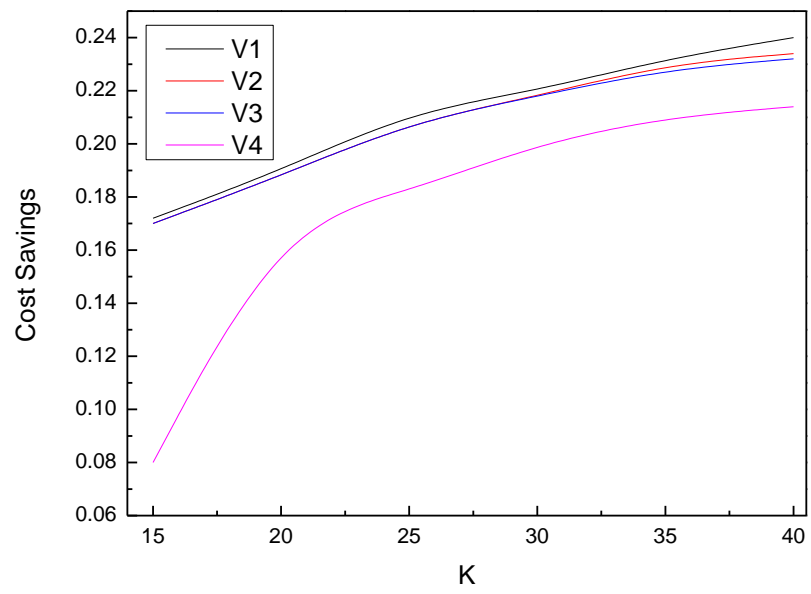

Figure 3. Influence Rate of Ordering Costs for Saving Cost

When the delivery time is fixed, the other factors values according to the Table 3 . We can get the dispersion degree in the figures 2 under the QS_R strategy demand rate. When the delivery time is constant, the greater demand vectors $i$, the higher vector of the variance. Therefore, saving cost effect of QS_R strategy is worse. 


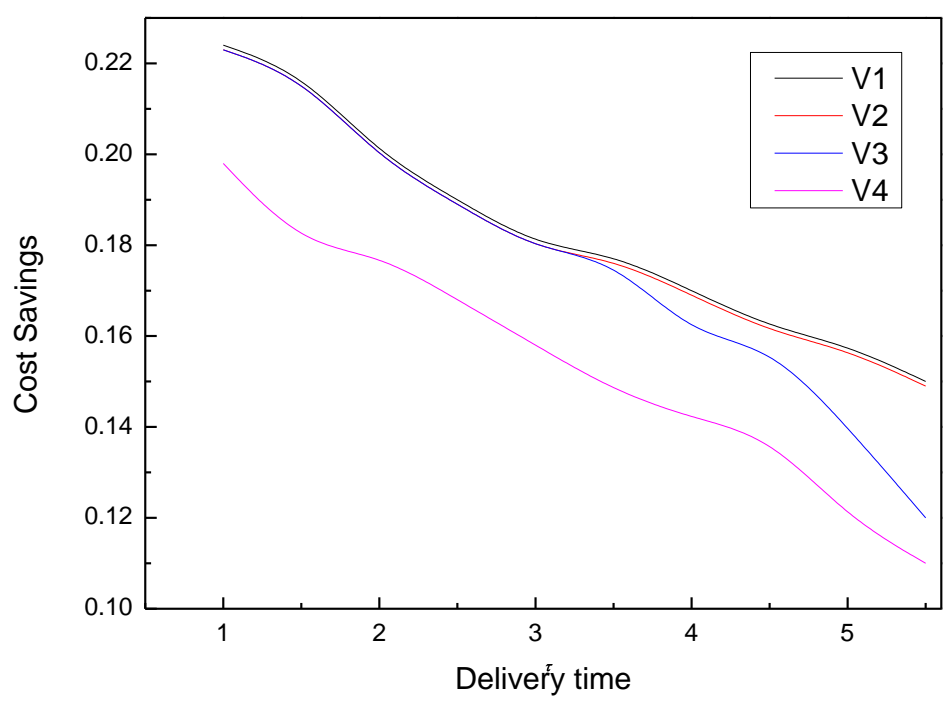

Figure 4. The Influence of Delivery Time on Saving Cost

When the $\mathrm{K}$ is constant, with the change in delivery time, we can see the extent of the saving cost of QS_R strategy. We know that the delivery time becomes longer, and the frequency of orders becomes lower in the same period. Correspondingly, fixed ordering cost will be reducing. Therefore, when the delivery time becomes longer, QS_R strategy will perform worse in total saving cost.

Table 3. Optimal Control Variable Table

\begin{tabular}{|c|c|c|c|c|c|c|c|c|c|}
\hline $\begin{array}{c}\text { delivery } \\
\text { time }\end{array}$ & K & $r_{1}^{*}$ & $r_{2}^{*}$ & $r_{3}^{*}$ & $Q^{*}$ & $S_{i}^{*}$ & profit & $\begin{array}{c}\text { Original } \\
\text { profit } \\
*_{2}\end{array}$ & $\begin{array}{c}\text { Rate of } \\
\text { profit } \\
\text { increase } \\
\%\end{array}$ \\
\hline 4 & 15 & 1 & 2 & 0 & 31 & $\begin{array}{l}51 \\
57 \\
47 \\
46\end{array}$ & 167.868 & 157.506 & 6.18 \\
\hline 3.5 & 20 & 1 & 2 & 0 & 34 & $\begin{array}{l}52 \\
43 \\
42\end{array}$ & 166.764 & 156.204 & 6.32 \\
\hline 3 & 25 & 1 & 2 & 0 & 38 & $\begin{array}{l}46 \\
38 \\
36\end{array}$ & 166.137 & 155.327 & 6.50 \\
\hline 2.5 & 30 & 1 & 2 & 0 & 38 & $\begin{array}{l}40 \\
33\end{array}$ & 165.794 & 154.713 & 6.69 \\
\hline 2 & 42 & 1 & 2 & 0 & 40 & $\begin{array}{l}35 \\
28 \\
33 \\
20\end{array}$ & 166.12 & 154.4348 & 7.10 \\
\hline
\end{tabular}

Note: $\mathrm{c}=30 ; \mathrm{p}=40 ; \lambda=(8,8,9) ; \delta_{1}^{t}=\delta_{2}^{t}=\delta_{3}^{t}=0.1 ; \delta_{1}^{r}=\delta_{2}^{r}=\delta_{3}^{r}=(8,3)^{* 1} ; \delta_{f}=1 ; * 1$ $3 \mathrm{CSF}$ the rent in the city is 8 , the rent in the suburbs is 3 ; $* 2$ without considering the impact on $3 \mathrm{CS}$ 


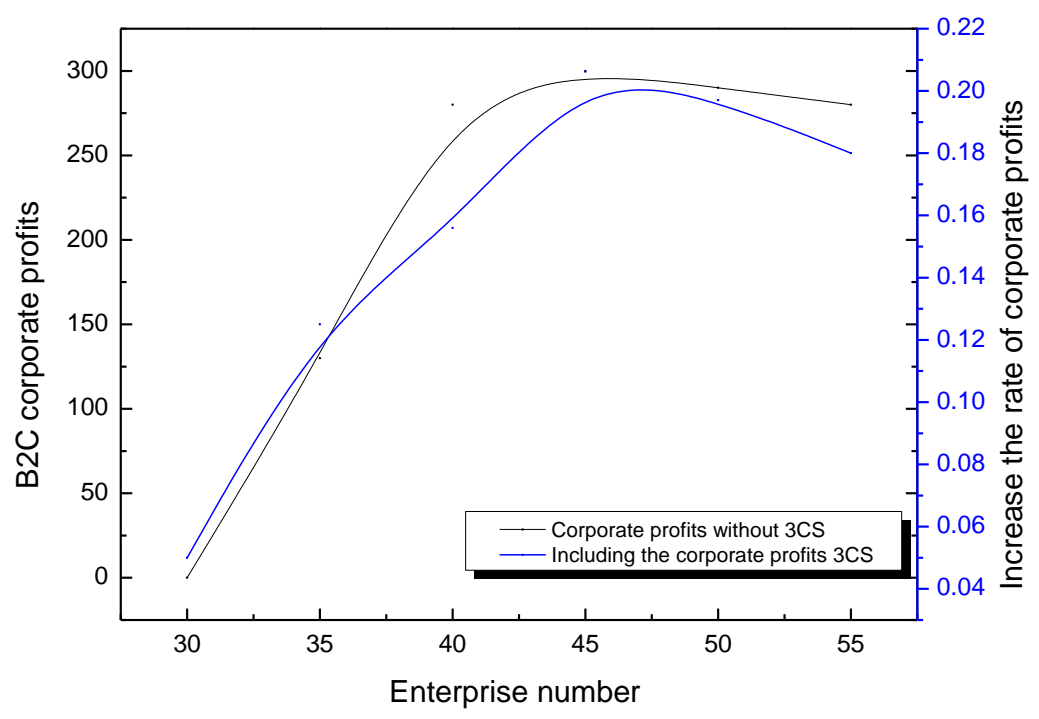

Figure 5. Sensitivity Analysis of the Price of Retail Enterprises for Business Profitability

We assume that $\lambda_{i}^{\prime}=a_{i}-p / 4$ which based on historical data of $\mathrm{B} 2 \mathrm{C}$ companies. So we regardless of the $3 \mathrm{CS}$, there should be an optimal retail price to make enterprises' profits maximize. These phenomena are reflected in Figure 4 and 5. When the retail price in the lower level, with prices rising, we regardless of the $3 \mathrm{CS}$, the profit of $\mathrm{B} 2 \mathrm{C}$ business has increased significantly. But when the price exceeds a certain critical point, the profit of $\mathrm{B} 2 \mathrm{C}$ business will decrease as prices rise.

\section{Conclusion}

This paper focuses on the reverse logistics model in e-commerce models. First, we analyzed and summarized this model. Because of rapid development and the combination of e-commerce and logistics, the technology has been widely popularization in large and medium enterprises. And then we carefully analyze the factors that they can trigger reverse logistics. We further analyze the important point by building models. Therefore, the model is still in its infancy. We should carry out the further optimization and improvement, and make it better serve the network environment.

\section{References}

[1] Stock J R.Development and implementation of reverse logistics programs. Oak Brook IL: Council of logistics Management, 1998. 53-67

[2] Kopichi R.Reuse and recycling-Reverse logistics opportunities. Oak Brook IL: Council logistics Management, 1993.3-52

[3] KaPlan R.S. And Norton D.P. The balanced scorecard-measures that drive Performance [J] Harvard Business Review.Jan.feb.1992:71-79

[4] Dennis W.Krumwiedea, Chwen Sheu. A model for reverse logistics entry by third-party Providers [J].Omega,2002,30:325-333

[5] Guide VDR, Jayaraman V, Srivastava R,Benton W C.Supply-chain management for recoverable manufacturing systems[J].Interfaces 2000;30(3):125-42

[6] Rogers D, Lambert D, Croxton K,Garcia-Dastugue S. There tums management process[J]. Int.J Logistics Manage, 2002, 13: 1-17 
[7] Murphy P R, Poist R F. Green logistics strategies: ananalysis of usage patterns [J].Transportation Journal,2000, 40(2):5-16

[8] Viswanathan S.,Note:Periodic review(s,S) Policies for joint replenishment inventory systems.[J] Management Science,1997,43(10):1447-1454

[9] Wang,Z., Huang,P., Case study of the development of electronic commerce in Shanghai[R] Shanghai, Shanghai Jiao Tong University, 2004:15-20

[10] Wong, X.D., Yen, D., Fang, X., E-commerce development in China and its implication for business [J]. Asia Pacific Journal of Marketing and Logistics, 2004, 16(3):68-83

\section{Author}

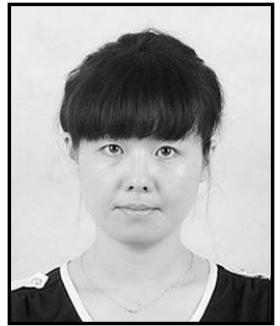

CHEN Ling-ling, female, she was born in 1984 in Tangshan, Hebei province. She is wuhan university of science and doctoral students. Now she works at Yanching Institute of Technology as a lecturer. Her research direction is transportation logistics management. 